\section{Italian professorships}

SIR - The most recent round of applications (concorsi) for full university professorship throughout Italy is just struggling to a close. It seems that things are at last changing, and that the move of protest is registering its first results.

Those who want the system changed say that the scandalous pressure on candidates, teachers and committees must be outlawed. Computerized analyses of scientific publications allow immediate comparison of applicants by objective parameters. The impact factor and citation index can no longer be ignored as objective approaches to evaluation of scientific candidates. Two examples (see figure) demonstrate the clear superiority of our record compared to the majority of the successful candidates. Our applications were nevertheless unsuccessful. To add insult to injury, the weakest winners were
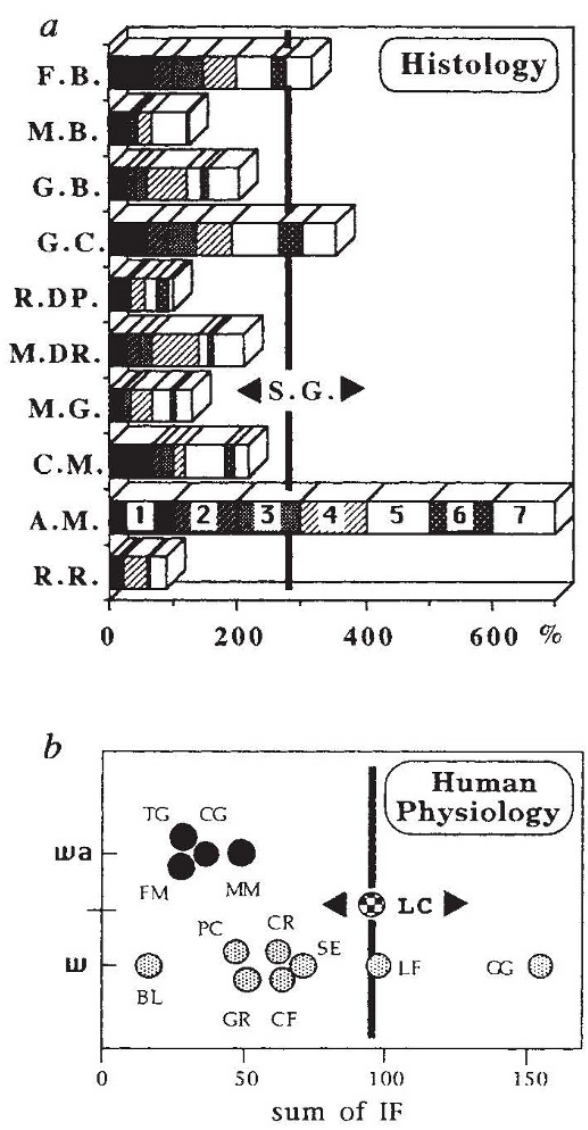

a. The scientific weight of the ten histology winners, expressed as percentages of leader's values (A.M.), and compared to the weight of the present author S.G.: (1) number of papers, (2) sum of the impact factors (IF*), (3) sum of normalized IFs (IF/number of co-authors), (4) average IF, (5) number of papers as first or senior author (FS), (6) sum of IFs as FS, (7) average IF as FS. $b$. The scientific weight (as total IF) of the 12 human physiology winners (black and grey circles; $w+w a)$ compared to the writer L.C. The winners indicated by the black circles (wa) were collaborators of the committees. collaborators of commission members the usual outcome of the present concorsi system.

We, together with others from other faculties, organized a series of national meetings, which led to the creation, in mid-February, of the Academic Research and Culture Association (ARCA). According to press reports, the public prosecutor of Rome has opened an enquiry into a number of concorsi, on the basis of our dossier. The universities of Rome, Padua, Cagliari, Milan, Florence and Naples, which are under investigation, have cause to be concerned, given the criminal conviction of the medical faculty commission chairman for abuse of authority.

Prevention of abuse is equally if not more crucial. It is here that ARCA will have a role, by promoting the best academic candidates in Italy. ARCA will recommend approaches that include the use of objective parameters in the selection procedures for academic promotions and distribution of research funds, in the assessment of academic output at all levels, and in the setting up of tight controls over commission membership. Padua university has opened the way: medical faculty rules approved on 23 February set an 'impact factor' threshold for future members of its scientific and development commissions, and its promotion commission is now adopting objective parameters.

The universities in Italy, with their newly acquired financial and managerial autonomy from the research ministry, will have to improve their cost-quality ratios to survive in the national and international arena, and this in turn should restore the cultural and ethical basis on which they were originally founded.

\section{Laura Calza}

Institute of Human Physiology.

University of Cagliari,

Cagliari,

Italy

Spiridione Garbisa

Institute of Histology

and Embryology,

University of Padova,

Via Trieste 75 ,

35121 Padova.

Italy

\section{Earthquake hazard}

SIR - Your rather glum conclusions about the seismological lessons from the Kobe earthquake (Nature 373, 269; 1995) are off base to the extent that they imply that seismology has little to offer hazard mitigation, and that more engineering is the answer.
Such statements as "seismic waves themselves do not kill people in large numbers. But buildings and other components of the built environment do", or "Experience... has amply shown what benefits can accrue from buildings designed against earthquakes" conceal a fundamental logical inconsistency. Engineers cannot design earthquakeresistant buildings without knowing how the ground is likely to shake when an earthquake occurs. Building codes are based on estimates of ground motion. Ground motion is determined by the shallow geological structure beneath buildings, the deeper structure between the earthquake and buildings, the location of the earthquake relative to the building, and properties of the earthquake source. Knowledge of these factors comes from seismological studies.

Engineers and scientists alike will agree that where this information is accurate and appropriately accounted for in the building codes, lives have been saved. Indeed, the destruction following the Kobe earthquake would have been far worse had there not been this partnership between seismologists and engineers.

As you correctly suggest, the costs of building seismically safe structures (where 'safety' is defined relative to the likely seismic motions, assuming such estimates exist) may be extremely high. Seismic zonation, which quantifies the variability in probable earthquake occurrence and consequent shaking, provides a demonstrably effective way to minimize this cost. This is the realm of seismology, not engineering.

It is short-sighted to imply that seismology has failed because experimentation in earthquake prediction has not yet resulted in "the prize seismology should deliver". Outside Japan, research for explicit earthquake prediction experiments receives a relatively small part of monies spent on seismology. Societies spend orders of magnitude more on the search for a general cancer cure though most would agree that it, too, is "an impossible dream for the present".

Like the failure to find a cancer cure, the failure to predict an earthquake does not signify a failure of earthquake prediction research. Rather, the research process has yielded valuable advances in our understanding of the causes and effects of earthquakes, understanding useful for both short- and long-term mitigation of earthquake hazard.

\section{Paul Bodin}

Center for Earthquake Research

and Information,

\section{Joan Gomberg}

United States Geologica/ Survey,

Center for Earthquake Research

and Information,

University of Memphis,

Memphis, Tennessee 38152, USA 